Revista Brasileira de Agricultura Irrigada v.11, nº.7, p. 1934 - 1944, 2017

ISSN 1982-7679 (On-line)

Fortaleza, CE, INOVAGRI - http://www.inovagri.org.br

DOI: $10.7127 /$ rbai.v11n700657

Protocolo 657.17 - 06/04/2017 Aprovado em 06/08/2017

\title{
CRESCIMENTO E SOLUTOS ORGÂNICOS DO FEIJÃO-CAUPI SUBMETIDO A NÍVEIS DE SALINIDADE DA ÁGUA DE IRRIGAÇÃO
}

Laís Monique Gomes do Ó ${ }^{1}$, Tiago Cavalcante da Silva², Geocleber Gomes de Sousa ${ }^{3}$, Kleiton Rocha Saraiva ${ }^{4}$, Maria Vanessa Pires de Souza ${ }^{5}$

\begin{abstract}
RESUMO
O manejo inadequado da irrigação tem causado a salinização dos solos, provocando reduções nas características morfológicas das culturas em geral. Nesse sentido, objetivou-se avaliar os efeitos de diferentes níveis de salinidade da água de irrigação sobre o comportamento morfológico de duas cultivares de feijão-caupi. O experimento foi conduzido em vasos a céu aberto, na área experimental da Estação Agrometeorológica da Universidade Federal do Ceará, Fortaleza, Ceará. Utilizou-se o delineamento estatístico de blocos ao acaso com parcelas subdivididas (Split-plot), onde os níveis de salinidade foram distribuídos nas parcelas $\left(\mathrm{S} 1=0,7 \mathrm{dS} \mathrm{m}{ }^{-1} ; \mathrm{S} 2=1,5 \mathrm{dS} \mathrm{m}{ }^{-1} ; \mathrm{S} 3=3,0 \mathrm{dS} \mathrm{m}{ }^{-1} ; \mathrm{S} 4=4,5 \mathrm{dS} \mathrm{m}^{-1} ; \mathrm{S} 5=6,0 \mathrm{dS} \mathrm{m}^{-1}\right.$ ), e nas subparcelas as cultivares (Epace 10 e BRS Itaim). As variáveis avaliadas foram: altura das plantas, número de folhas, diâmetro do caule e área foliar, carboidratos solúveis totais, $\mathrm{N}$ aminossolúveis e prolina livre. A cultivar Epace 10 apresenta maior tolerância em relação a cultivar Itaim para as variáveis altura de plantas, diâmetro do caule, área foliar, carboidratos solúveis totais e $\mathrm{N}$ - aminossoluveis. A cultivar BRS Itaim apresentou maior concentração do teor de prolina frente à imposição do estresse salino.
\end{abstract}

Palavras-chave: Vigna unguiculata (L) Walp., características morfológicas, estresse salino

\section{GROWTH AND ORGANIC SOLUTIONS OF COWPEA SUBMITTED TO SALINITY LEVELS OF IRRIGATION WATER}

\begin{abstract}
The inadequate management of irrigation has caused soil salinization, causing reductions in the morphological characteristics of crops in general. The objective of this study was to evaluate the effects of different irrigation water salinity levels on the morphological behavior of two cowpea cultivars. The experiment was conducted in open air vessels, in the

\footnotetext{
${ }^{1}$ Engenheira Agrônoma. Universidade Federal do Ceará - UFC. E-mail: laisnique@hotmail.com

${ }^{2}$ Engenheiro Agrônomo. Universidade Federal do Ceará - UFC. E-mail: tiago.cavalcantesilva@hotmail.com

${ }^{3}$ Doutor em Engenharia Agrícola. Docente da UNILAB. E-mail: sousasolosgeo@hotmail.com

${ }^{4}$ Doutor em Engenharia Agrícola. Docente do IFPI. E-mail: kleiton.rocha@ifpi.edu.br

${ }^{5}$ Discente de Agronomia. UNILAB. E-mail: vanessa.pires1993@gmail.com
} 
experimental area of the Agrometereological Station of the Federal University of Ceará, Fortaleza, Ceará. A randomized complete block design with split-plot was used, where the salinity levels were distributed in the plots (S1 $=0.7 \mathrm{dS} \mathrm{m}^{-1}$; S2 $=1.5 \mathrm{dS} \mathrm{m}^{-1}$; S3 $=3.0 \mathrm{dS} \mathrm{m}^{-1}$; $\mathrm{S} 4=4.5 \mathrm{dS} \mathrm{m}^{-1}$; S5 $=6.0 \mathrm{dS} \mathrm{m}^{-1}$ ), and in the subplots the cultivars (Epace 10 and BRS Itaim). The evaluated variables were: plant height, number of leaves, stem diameter and leaf area, total soluble carbohydrates, $\mathrm{N}$ - aminosoluble and free proline. The cultivar Epace 10 showed higher tolerance in relation to the Itaim cultivar in plant height, stem diameter, leaf area, total soluble carbohydrates and $\mathrm{N}$ - aminosoluble. The cultivar BRS Itaim presented higher concentration of the proline content against the imposition of salt stress.

Keywords: Vigna unguiculata (L) Walp., morphological characteristics, salt stress

\section{INTRODUÇÃO}

O feijão-caupi (Vigna unguiculata L.) é a principal cultura de subsistência e fonte de proteína de origem vegetal do pequeno produtor da região semiárida nordestina. Cultura essa considerada de subsistência ou comercial nas regiões Norte e Nordeste do Brasil, gerando emprego e renda. Trata-se de uma leguminosa altamente nutritiva, de boa aceitação no mercado e um dos principais componentes da dieta alimentar da população do Nordeste brasileiro (LIMA et al., 2007).

No Nordeste brasileiro as águas utilizadas nas irrigações apresentam, na maioria das vezes, concentração de sais na faixa de 1 a $30 \mathrm{mmol}_{\mathrm{c}} \mathrm{L}^{-1}$ correspondendo à faixa de condutividade elétrica de 0,1 a 3,0 dS $\mathrm{m}^{-1}$, poderá o seu uso na agricultura, aliado a intensa evaporação e à falta de drenagem de solo adequada, provocar problemas de salinidade (HOLANDA; AMORIM, 1997). Em função disso, a verificação da adequabilidade da água para fins de irrigação deve considerar, principalmente, fatores relacionados ao teor e tipo de sais, às características do solo, tolerância da cultura, condições climáticas, manejo da irrigação e condições de drenagem (RHOADES et al., 2000).

Dentre as práticas de manejo
recomendadas satisfatoriamente em condições de solo e água com altos riscos de salinização, se destacam o uso de plantas tolerantes à salinidade e à sodicidade, manejo adequado da irrigação e controle da salinidade do solo com aplicação de lâminas de lixiviação, tornando-se importantes os estudos que visem avaliar a sensibilidade das espécies ao estresse salino (TRAVASSOS et al., 2012).

A salinidade inibe o crescimento e a produtividade na maioria das culturas, cuja resposta é atribuída ao desbalanceamento nas relações hídricas e nutricionais das plantas e ao acúmulo de íons considerados tóxicos (LACERDA et al., 2011; PRAZERES et al., 2015). Como resposta, uma adaptação fisiológica importante utilizada pela maioria das plantas para minimizar os efeitos do estresse salino, é o ajustamento osmótico. Tal ajuste induz ao acúmulo de solutos orgânicos (como alguns açúcares e aminoácidos) e inorgânicos nos tecidos proporcionando redução no potencial osmótico da célula, evitando a perda de turgescência ao gerar um potencial hídrico mais baixo (WILLADINO; CAMARA, 2004; TAIZ; ZAIGER, 2013).

Calvet et al. (2013) avaliando o feijão de corda submetido a salinidade em diferentes fases do desenvolvimento das plantas, no que concerne aos teores dos solutos orgânicos e inorgânicos das folhas, caules e raízes, concluíram que o teor de cloreto das plantas estressadas foi maior nas folhas e o de sódio foi mais elevado nos caules. Já os teores de carboidratos das raízes foram elevados pelo tratamento salino, nas fases de floração até a frutificação. Neste contexto o objetivo desse trabalho é avaliar o crescimento de plantas de feijão-caupi submetidas a níveis de salinidade da água de irrigação com as cultivares BRS Itaim e Epace 10.

\section{MATERIAL E MÉTODOS}


O experimento foi conduzido na área experimental da Estação Agrometeorológica da Universidade Federal do Ceará (UFC), Fortaleza, Ceará, coordenadas geográficas $03^{\circ} 45^{\prime} \mathrm{S}, 38^{\circ} 33^{\prime} \mathrm{W}$, altitude média $19 \mathrm{~m}$, no período de outubro a dezembro de 2014.

O clima da região, segundo a classificação de Köppen, é do tipo Aw', tropical chuvoso, com temperaturas elevadas e com estação chuvosa predominante no outono. A temperatura média mensal durante a condução do experimento foi de $27,4{ }^{\circ} \mathrm{C}$, a umidade relativa foi de $70 \%$ e a precipitação de $14,4 \mathrm{~mm}$.

Como substrato para o cultivo das plantas, foi utilizado um Argissolo VermelhoAmarelo (EMBRAPA, 2013), oriunda de uma área com vegetação nativa, localizada próximo a área experimental, coletadas na profundidade de $0-0,20 \mathrm{~m}$.

Foram utilizadas duas cultivares de feijoeiro Epace 10 e BRS Itaim, produzidas pela Empresa de Pesquisa Agropecuária do Ceará e Embrapa Meio Norte, respectivamente. Os vasos com capacidade volumétrica de $15 \mathrm{~L}$ foram preenchidos com uma camada de brita $\mathrm{n}^{0} 1$, para facilitar a livre drenagem do excedente hídrico. Na sequência, procedeu-se com o preenchimento dos vasos, constituído por um substrato formado por uma mistura do solo local e composto orgânico de húmus de minhoca na proporção de 2:1.

O plantio foi feito semeando-se em média de três a quatro sementes por vaso. Aos 7 dias após a semeadura (DAS), observou-se uma germinação de aproximadamente $90 \%$. No desbaste, realizado manualmente aos 10 DAS, as plantas foram arrancadas rente ao solo, deixando-se duas plantas por vaso.

O delineamento estatístico foi o de blocos ao acaso com parcelas subdivididas (Split-plot), onde as parcelas foram compostas pelos os níveis de salinidade ( $\mathrm{S} 1=0,7 \mathrm{dS} \mathrm{m}^{-1}$; $\mathrm{S} 2=1,5 \mathrm{dS} \mathrm{m}^{-1} ; \mathrm{S} 3=3,0 \mathrm{dS} \mathrm{m}^{-1} ; \mathrm{S} 4=4,5 \mathrm{dS}$ $\mathrm{m}^{-1}$; $55=6,0 \mathrm{dS} \mathrm{m}^{-1}$ ) e as subparcelas pelas cultivares (EPACE e BRS Itaim), com cinco repetições.

Adotou-se o sistema de irrigação por gotejamento, utilizando-se emissores que foram previamente avaliados em campo, sob condições normais de operação, conforme a metodologia descrita por Keller e Karmelli (1975). Na ocasião, o sistema de irrigação foi testado adotando-se uma vazão nominal de $2 \mathrm{~L}$ $\mathrm{h}^{-1}$, cujo coeficiente de uniformidade de distribuição (CUD) apresentado foi de aproximadamente $90 \%$.

Para a determinação da estimativa diária da evapotranspiração de referência - Eto foi utilizado um tanque evaporímetro do tipo Classe A, localizado nas imediações da área experimental nos quais as leituras eram aferidas diariamente às $9 \mathrm{~h}$.

A evapotranspiração potencial da cultura foi estimada (ETpc), foi estimada através da equação 1 , mediante a multiplicação da evapotranspiração de referência e o coeficiente da cultura $(\mathrm{Kc})$, segundo Bernardo et al. (2006).

$$
E T p c=E T o . K c
$$

Em que, ETpc - Evapotranspiração potencial da cultura (mm); ETo Evapotranspiração de referência estimada através do Tanque Classe “A” (mm) e Kc Coeficientes de cultivo (0,70 até 12 DAP ; 0,81de 13 a 33 DAP; 1,2 de 34 a 54 DAP e 0,77de 55 DAP até o final do ciclo, conforme o proposto por Sousa et al. (2005).

Já o tempo de irrigação, utilizado foi calculado a partir da equação 2 :

$$
T_{I}=\frac{E T p c \cdot A_{v}}{C U D \cdot q_{g}}
$$

Em que, TI - Tempo de irrigação (h); ETpc - Evapotranspiração potencial da cultura (mm); $A_{v}$ - Área do vaso (0, $\left.0706 \mathrm{~m}^{2}\right)$; CUD Coeficiente de uniformidade de distribuição de água do sistema de irrigação (Valor obtido em avaliação, CUD = 0,90) e qg - Vazão do gotejador, $\mathrm{L} \mathrm{h}^{-1}\left(\mathrm{qg}_{\mathrm{g}}=2 \mathrm{~L} \mathrm{~h}^{-1}\right)$.

Após o plantio das sementes de feijãocaupi, o experimento foi irrigado diariamente com uma lâmina equivalente a $100 \%$ da evapotranspiração potencial da cultura - ETpc, 
com uma frequência equivalente há dois dias consecutivos.

A água salina utilizada nas irrigações, proveniente de um poço freático, era armazenada em reservatórios com capacidade de 310 L. A quantidade dos sais $\mathrm{NaCl}$, $\mathrm{CaCl}_{2} .2 \mathrm{H}_{2} \mathrm{O}$ e $\mathrm{MgCl}_{2} .6 \mathrm{H}_{2} \mathrm{O}$, utilizadas no preparo das águas de irrigação foi determinada de forma a se obter a CEa desejada na proporção 7:2:1, conforme Rhoades et al. (2000).

Aos 45 dias após o plantio (DAP), a fim de mensurar os efeitos dos diferentes tratamentos foram determinadas as seguintes variáveis: altura das plantas (aferida por meio de trena graduada) diâmetro do caule (considerada a distância entre o colo da planta), número de folhas (missão da folha mais nova), área foliar (utilizando um integrador de área (LI-3100, Li-Cor, Inc. Lincoln, NE, USA), carboidratos solúveis totais (determinados pelo método desenvolvido por Dubois et al. (1956)), N aminossolúveis (determinada de acordo com o método de Yemm e Cocking (1955)) e prolina livre (determinada de acordo com a metodologia proposta por Bates et al. (1973)).
Os resultados foram submetidos à análise de variância e de regressão e, as médias comparadas pelo teste de Tukey com $\mathrm{P}$ $<0,05$, utilizando-se o programa SAEG/ UFV. $\mathrm{Na}$ análise de regressão, as equações de regressão que melhor se ajustarem aos dados foram escolhidas com base na significância dos coeficientes de regressão ao nível de significância de $1 \%(* *)$ e $5 \%(*)$ pelo teste $\mathrm{F}$, e no maior coeficiente de determinação $\left(\mathrm{R}^{2}\right)$.

\section{RESULTADOS E DISCUSSÃO}

O resumo das análises de variância para os dados morfológicos de altura de plantas (h), diâmetro do caule (Øc), número de folhas $\left(\mathrm{N}_{\mathrm{f}}\right)$ e área foliar $\left(\mathrm{A}_{\mathrm{F}}\right)$ do feijoeiro caupi pode ser observado na Tabela 1. Houve influência significativa em nível de $1 \%$ de probabilidade pelo teste $\mathrm{F}$ nos tratamentos de níveis de salinidade sobre todas as variáveis estudadas. As cultivares apresentaram significância para altura das plantas a nível de $1 \%$ e para as variáveis diâmetro do caule e área foliar a nível de 5\%. Houve interação entre os tratamentos para a variável diâmetro do caule a nível de 5\%.

Tabela 1. Resumo da análise de variância para os dados de altura das plantas (h), diâmetro do caule (øc), número de folhas (Nf) e Área foliar (Af) do feijão-caupi submetido a níveis de salinidade

\begin{tabular}{cccccc}
\hline & & \multicolumn{4}{c}{ Quadrados médios } \\
\cline { 3 - 6 } FV & GL & $\begin{array}{c}\mathrm{h} \\
(\mathrm{cm})\end{array}$ & $\begin{array}{c}\text { øc } \\
(\mathrm{mm})\end{array}$ & $\mathrm{Nf}$ & $\begin{array}{c}\text { Af } \\
\left(\mathrm{cm}^{2} \mathrm{planta}^{-1}\right)\end{array}$ \\
\hline $\begin{array}{c}\text { Blocos } \\
\text { Níveis de salinidade } \\
(\mathrm{N})\end{array}$ & 2 & $1,23^{\mathrm{ns}}$ & $0,14^{\mathrm{ns}}$ & $7,90^{\mathrm{ns}}$ & $70898,44^{* *}$ \\
Resíduo (N) & 8 & $114,88^{* *}$ & $11,21^{* *}$ & $90,41^{* *}$ & $1710424,25^{* *}$ \\
\hline Parcelas & 14 & 0,48 & 0,11 & 10,44 & 7305,38 \\
\hline Cultivares (C) & 1 & $38,53^{* *}$ & $0,99^{*}$ & $4,80^{\text {ns }}$ & $363636,07^{*}$ \\
Int. N x C & 4 & $1,28^{\text {ns }}$ & $0,76^{*}$ & $5,71^{\text {ns }}$ & $45327,83^{\text {ns }}$ \\
Resíduo (C) & 10 & 2,63 & 0,15 & 2,93 & 41180,1 \\
\hline Total & 29 & \multicolumn{5}{c}{} \\
\hline
\end{tabular}

$\mathrm{FV}=$ fonte de variação; $\mathrm{GL}=$ graus de liberdade; $\mathrm{CV}=$ coeficientes de variação; ${ }^{\text {ns }}$ - Não significativo, ${ }^{* *}-$ Significativo a $1 \%$ de probabilidade pelo teste $\mathrm{F} \mathrm{e}^{*}$ - Significativo a $5 \%$ de probabilidade pelo teste $\mathrm{F}$ 


\section{DA ÁGUA DE IRRIGAÇÃO}

Analisando o efeito dos níveis de salinidade sobre a variável altura das plantas constatou-se, a partir da análise que, o modelo de regressão matemático que melhor se ajustou aos dados desta variável foi o linear (Figura $1 \mathrm{~A})$.

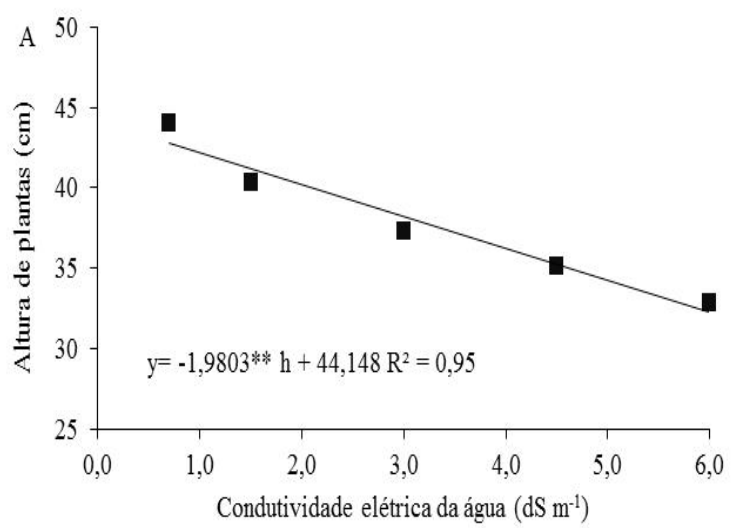

Figura 1A. Altura de plantas em função dos níveis de salinidade

Trabalhando com feijão-caupi cultivar EPACE 10, irrigado com água salina, Silva et al. (2011) observaram que os níveis crescentes de sais da água de irrigação prejudicaram o crescimento em altura de plantas. Apesar de pesquisarem com níveis de salinidade diferentes, mas utilizando a mesma cultivar, Lima et al. (2007), constataram uma redução em cerca de 42,86\% na altura, quando irrigadas com o maior nível salino, sendo encontrado neste trabalho uma redução de 25,39\%.

$\mathrm{Na}$ Figura 1B pode-se observar o comportamento entre as cultivares na variável altura de plantas. Os resultados mostram que a ultivar Epace 10 apresentou valores médios superiores de 39,06 cm em relação a BRS Itaim que foi de 36,8 $\mathrm{cm}$.

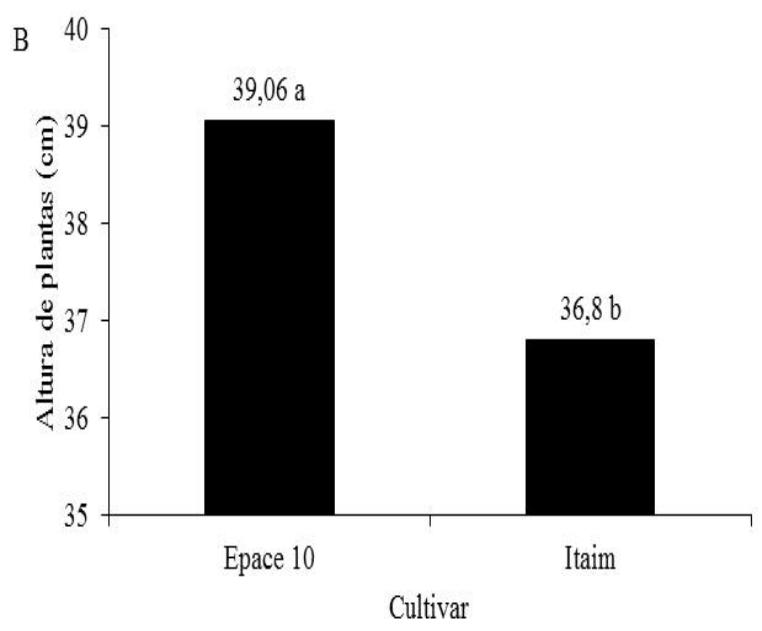

Figura 1B. Altura de plantas em função das cultivares

Esse resultado pode está relacionado a tolerância dessa cultivar, como reportam Neves et al. (2009). No entanto, Sousa et al. (2014) descrevem que a cultivar BRS Itaim pode ser cultivada com um nível salino de até $\left(3,5 \mathrm{dS} \mathrm{m}^{-1}\right)$, revelando um ajustamento osmótico dependendo do tipo de subtrato utilizado no cultivo.

Observando os efeitos dos níveis de salinidade sobre as variáveis, número de folhas e diâmetro do caule constatou-se, a partir da análise que, o modelo de regressão matemático que melhor representou a resposta da planta foi 0 linear (Figura 2A e 2B). 

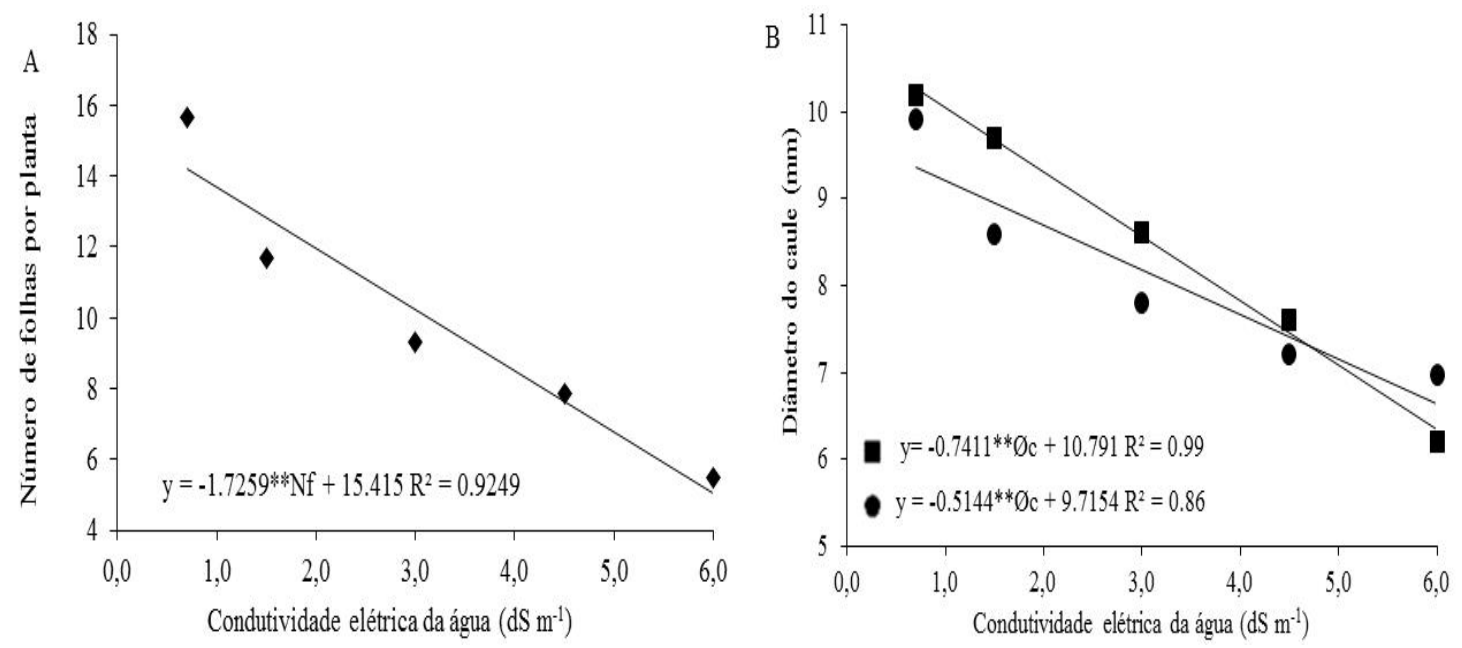

Figura 2. Número de folhas em função da condutividade elétrica da água (2A) e diâmetro do caule (2B) das cultivares Epace $10(\bullet)$ e BRS Itaim (•) em função da condutividade elétrica da água.

Esta redução do número de folhas para o maior nível de salinidade deve estar relacionada à possíveis mecanismos de adaptação da planta ao estresse salino consistindo no decréscimo da produção da área foliar, do fechamento dos estômatos, da aceleração da senescência e abscisão das folhas limitando não só o tamanho de folhas individuais, mas também o número de folhas por diminuir o número e a taxa de crescimento dos ramos (TAIZ; ZEIGER, 2013).

O diâmetro do caule das plantas de feijão-caupi foi negativamente afetado pelo incremento salino na água, com maior intensidade nos tratamentos com maior nível de salinidade. No entanto, foi a característica menos afetada pelas condições salinas estudadas, com uma redução de 39,05\% e $29,63 \%$ em relação aos tratamentos de menor

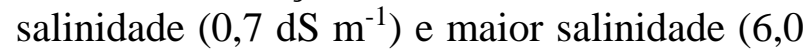
$\mathrm{dS} \mathrm{m}^{-1}$ ) na cultivar BRS Itaim e na cultivar Epace 10, respectivamente.

Para o efeito dos níveis de salinidade sobre a variável área foliar $\left(\mathrm{A}_{\mathrm{f}}\right)$, a análise de regressão mostrou que o modelo matemático que melhor representa os dados desta variável foi o tipo linear (Figura 3A). Provavelmente, a inibição da área foliar deve ter sido provocada, em maior parte, pelos efeitos tóxicos dos sais absorvidos pelas plantas, pela baixa capacidade de ajustamento osmótico da cultura ou pela redução do potencial total da água provocado pelo aumento da concentração salina (LARCHER, 2006).

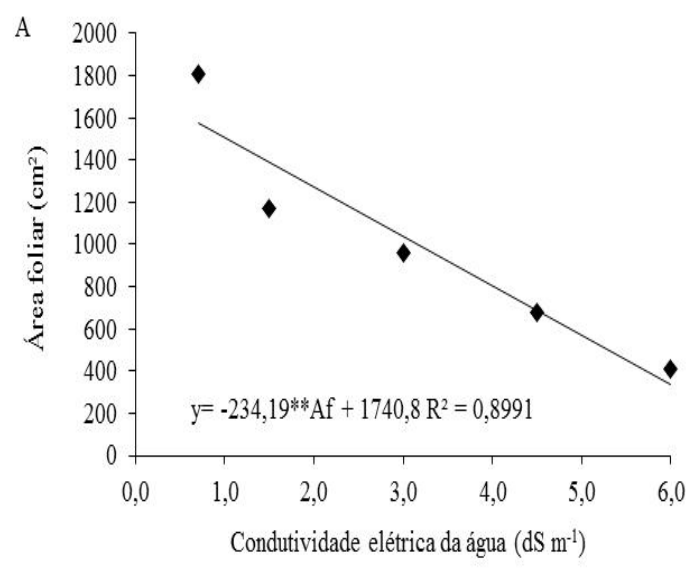

Figura 3A. Área foliar das cultivares Epace 10 e BRS Itaim em função dos níveis de salinidade.

Os valores médios da variável área foliar podem ser visualizados na Figura 3B. Os resultados mostram que a cultivar Epace 10 apresentou superioridade de 19,74 \% em relação a BRS Itaim, com valores de 1115,55 $\mathrm{cm}^{2}$ e 895,36 $\mathrm{cm}^{2}$, respectivamente. 


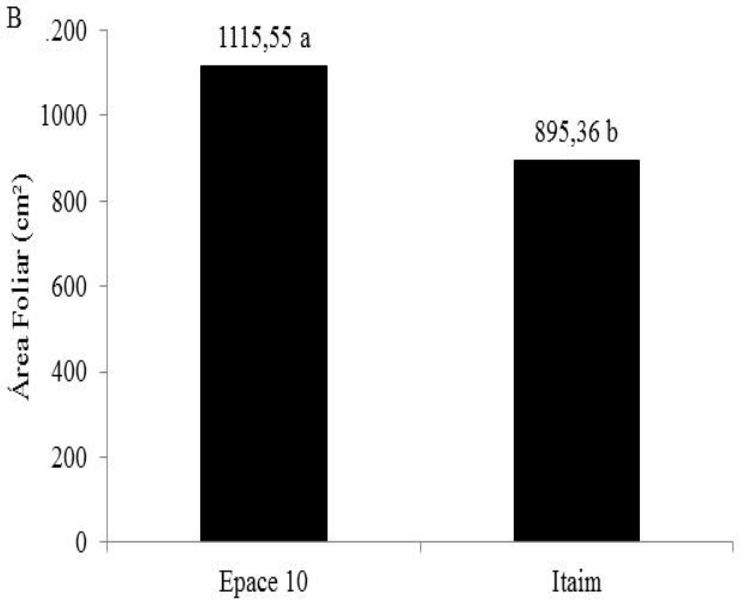

Figura 3B. Área foliar das cultivares Epace 10 e BRS Itaim em função dos níveis de salinidade

Similar a este resultado, Araújo et al. (2010), observaram em seu experimento com feijoeiro, que a área foliar das quatro cultivares estudadas decresceu com o incremento da salinidade.
Os resultados da análise de variância dos teores de solutos orgânicos, carboidratos solúveis, $\mathrm{N}$ - aminossolúveis e prolina livre estão expostos na Tabela 2. Verificou-se que os níveis de salinidade (N) afetaram significativamente os teores foliares de carboidratos solúveis e prolina a nível de 1\%, e $\mathrm{N}$ - aminossolúveis a nível de $5 \%$ de probalidade, pelo teste F. Já no fator cultivares (C) analisadas, apresentaram diferença significativa nos teores de carboidratos solúveis e prolina a nível de $5 \%$ de probabilidade, e $\mathrm{N}$ - aminissolúveis a $1 \%$ de probabilidade, pelo teste $\mathrm{F}$. Por sua vez, os fatores níveis de salinidade $(\mathrm{N})$ e cultivares (C) atuaram conjuntamente, promovendo alterações nos teores foliares de prolina livre (PR), a nível de probabilidade de $1 \%$, tornando a interação $\mathrm{N} \mathrm{x}$ $\mathrm{C}$ significativa, de acordo com o teste $\mathrm{F}$ (Tabela

Tabela 2. Resumo das análises de variâncias para os dados teores dos solutos orgânicos carboidratos solúveis (CS), $\mathrm{N}$ - aminossolúveis ( $\mathrm{N}$ - amin.) e prolina livre (PR) em folhas de feijoeiro caupi, submetidas a diferentes níveis de salinidade

\begin{tabular}{lcccc}
\hline \multirow{2}{*}{ FV } & GL & \multicolumn{3}{c}{ Quadrados médios } \\
\cline { 3 - 5 } & 2 & $4725,01^{\text {ns }}$ & N - Amin. & PR \\
\hline Blocos & 4 & $729980.18^{* *}$ & $176,28^{\text {ns }}$ & $0,07^{\text {ns }}$ \\
Níveis de salinidade (N) & 8 & 18432,47 & 26,12 & $30,65^{* *}$ \\
Resíduo - (N) & 14 & - & - & -11 \\
\hline Parcelas & 1 & $206760,09^{*}$ & $76,59^{* *}$ & $3,12^{*}$ \\
\hline Cultivares (C) & 4 & $23616,73^{\text {ns }}$ & $5,45^{\text {ns }}$ & $0,009^{* *}$ \\
Int. N x C & 10 & 25658,16 & 4,89 & 0,34 \\
Resíduo - (C) & 29 & & & \\
\hline Total & & 13,85 & 43,11 & 13,65 \\
\hline C.V. - N (\%) & & 16,34 & 18,66 & 7,62 \\
C.V. - C (\%) & & & & \\
\hline
\end{tabular}

Para os teores de carboidratos solúveis constatou-se, o modelo de regressão matemático que melhor se ajustou aos dados desta variável foi o linear. No que se relaciona aos efeitos dos diferentes níveis de salinidade sob os teores foliares de carboidratos solúveis, evidenciou-se que os valores se situaram entre 550 e $1300 \mu \mathrm{mol} \mathrm{g}^{-1}$ MS (Figura 4). 


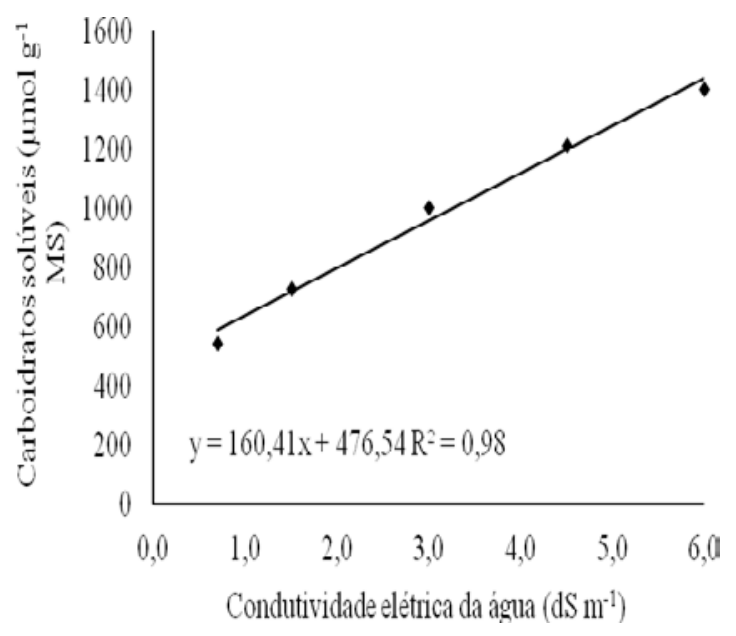

Figura 4. Carboidratos solúveis em folhas de feijão-de-corda submetido a níveis de salinidade.

Pedroso et al. (2014), afirmam que sob estresse salino, os carboidratos solúveis sintetizados nas folhas são usados para manter as atividades metabólicas que asseguram a sobrevivência da planta. Resultado similar ao desse estudo foi encontrado por Calvet et al. (2013) na cultura do feijão, cultivar EPACE 10.

Os efeitos da salinidade sobre os teores de carboidratos solúveis nas folhas das cultivares analisadas, apresentaram diferença significativa. Tendo a cultivar Epace 10 o maior acumulo, 1063,26 $\mu_{\mathrm{mol} \mathrm{g}}{ }^{-1} \mathrm{MS}$, e a cultivar BRS Itaim 897,22 $\mu \mathrm{mol} \mathrm{g}^{-1}$ MS (Figura 5).

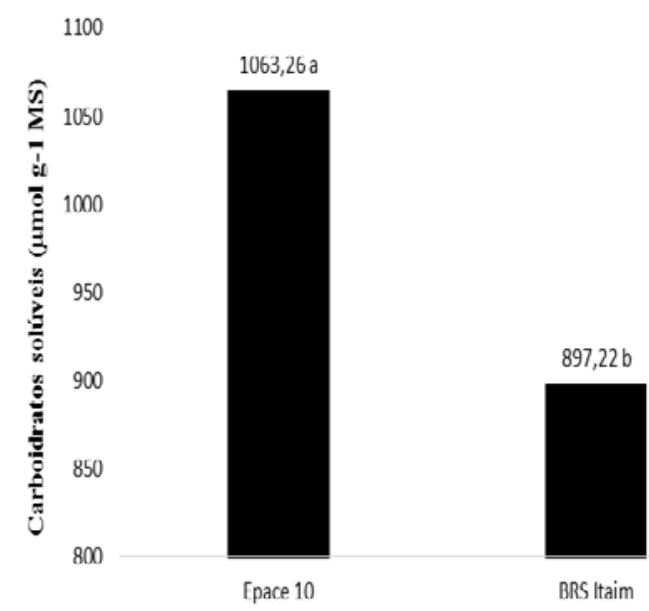

Figura 5. Teores de Carboidratos solúveis nas folhas de cultivares de feijão-de-corda, Epace 10 e BRS Itaim, submetido a níveis de salinidade da água de irrigação.
Essa condição adaptativa das plantas, que é ocasionada por algum tipo de estresse abiótico, gera uma acumulação de solutos compatíveis ao seu metabolismo, criando uma estratégia de tolerância a salinidade (MUNNS, 2002).

Analisando o efeito da salinidade na cultura do feijão-caupi, Praxedes et al. (2014) constataram que $\mathrm{o}$ teor de carboidratos solúveis totais diferiu conforme a fase fenológica da cultura ou cultivar utilizada.

Os teores foliares de $\mathrm{N}$ aminossolúveis aumentaram, consequentemente, com o aumento dos níveis de salinidade da água de irrigação (Figura 6).

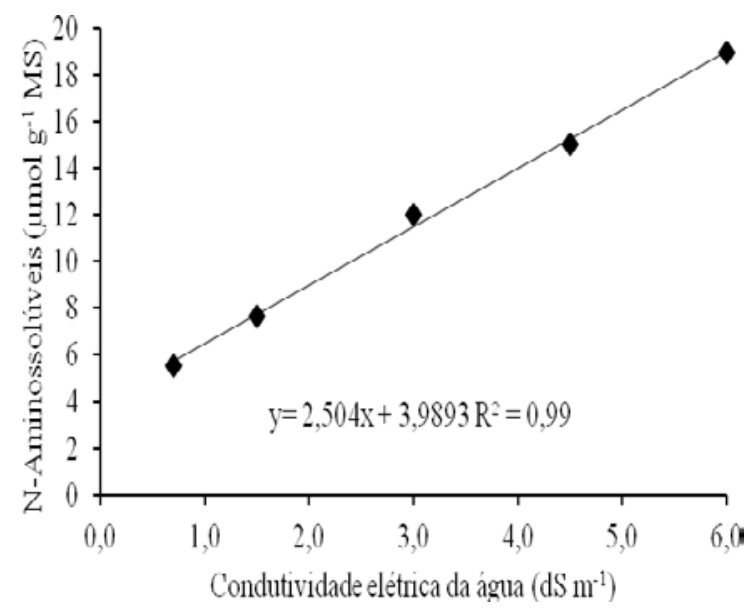

Figura 6. Teores de $\mathrm{N}$ - aminossolúveis em folhas de feijão-de-corda submetido a níveis de salinidade

Calvet et al. (2013), estudando o efeito dos níveis de salinidade no cultivar Epace 10, em suas diferentes fases, constataram que os níveis de $\mathrm{N}$ - aminossolúveis aumentaram nas folhas em todos os tratamentos avaliados sobre estresse salino, com menores valores desse acúmulo na primeira fase fenológica da planta. Pode ser evidenciado esse comportamento por Soussi et al. (1999) ao comprovarem que o maior acúmulo desse soluto é demonstrado durante a exposição das plantas à salinidade.

Quanto aos níveis de $\mathrm{N}$ - aminossolúveis nas cultivares avaliadas, pode-se observar um maior acúmulo no cultivar Epace 10, com $13,45 \mu \mathrm{mol} \mathrm{g}^{-1} \mathrm{MS}$ e no cultivar BRS Itaim 10,25 $\mathrm{mmol} \mathrm{g}^{-1} \mathrm{MS}$ (Figura 7). Praxedes et al. (2014) avaliando o efeito do estresse salino em duas cultivares de feijão vigna, identificadas 
como tolerante (Pitiúba) e sensível à salinidade (TVu 2331), observou que o acúmulo de $\mathrm{N}-$ aminossolúveis nas folhas nas cultivares só foi aumentado após a imposição das plantas ao estresse salino.

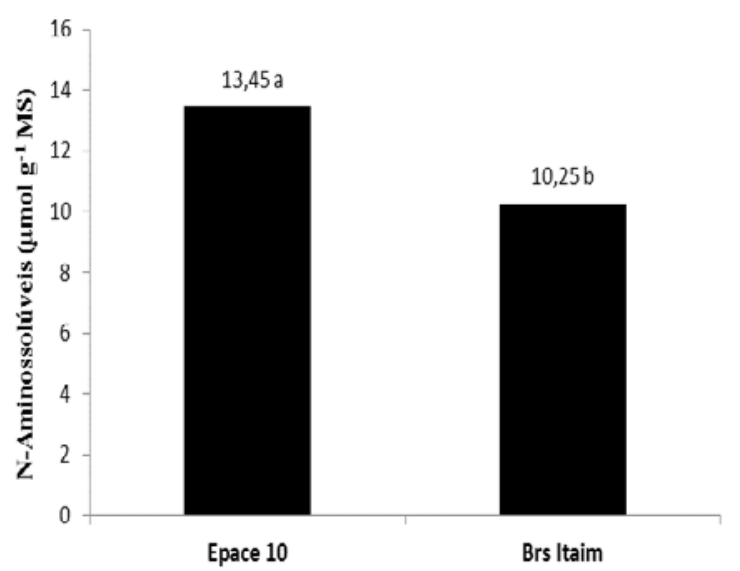

Figura 7. Teores de $\mathrm{N}$ - aminossolúveis nas folhas de cultivares de feijão-de-corda, submetido a níveis de salinidade da água de irrigação

Analisando-se o efeito da interação niveis de salinidade $\mathrm{x}$ cultivares (Figura 8), sobre a prolina livre nas folhas do feijão vigna, observou-se que o modelo matemático que melhor representou os dados desta variável foi do tipo linear.

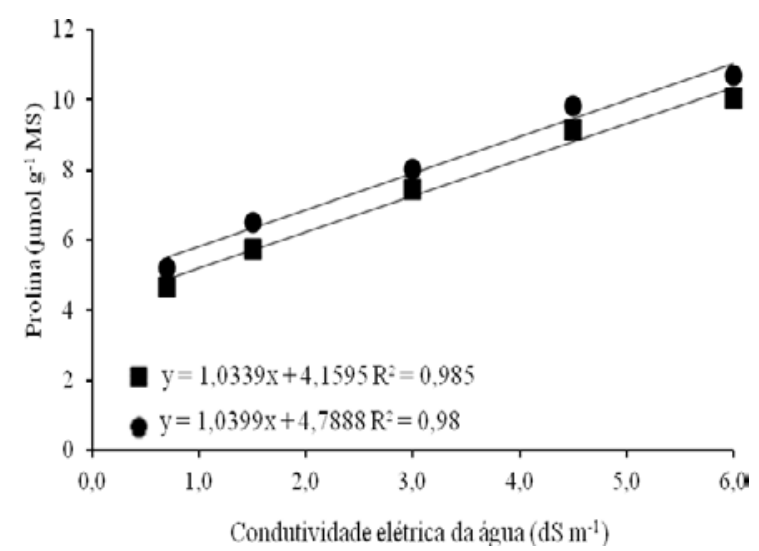

Figura 8. Teores de prolina das cultivares Epace 10 (•) e BRS Itaim (•) em função dos níveis de salinidade

Costa et al. (2003) trabalhando a influência da acumulação dos solutos orgânicos em cultivares de feijão vigna sob estresse salino, concluiram que o aumento de prolina livre em folhas e raízes está atribuído ao aumento na expressão da sintetase da $\Delta^{1}$ pirrolino-5-carbobxilato, enzima-chave na via biossintética da prolina (LIU; ZHU, 1997).

Souza et al. (2011), em estudo realizado com feijão vigna, cultivar Vita 7 e Calvet et al. (2013) a cultivar EPACE 10, constataram acúmulos significativos de prolina apenas quando os tratamentos foram submetidos a elevadas concentrações salinas.

\section{CONCLUSÕES}

A cultivar Epace 10 apresentou melhores variáveis de crescimento, com maior tolerância aos níveis de salinidade da água, em relação a cultivar Itaim, em altura de plantas, diâmetro do caule, área foliar, carboidratos solúveis totais e $\mathrm{N}$ - aminossoluveis.

O teor de prolina foi maior na cultivar Itaim do que na cultivar Epace 10, conforme se aumentou o estresse salino.

\section{REFERÊNCIAS}

ARAÚJO, C.A.S.; RUIZ, H.A.; CAMBRAIA, J.; NEVES, J.C.L.; FREIRE, M.B.G.S.; FREIRE, F. J. Seleção varietal de Phaseolus vulgaris quanto à tolerância ao estresse salino com base em variáveis de crescimento. Revista Ceres, v.57, n. 1, p. 2-4, 2010.

BATES, L. S.; WALDREN, R. P.; TEARE, I. D. Rapid determination of free proline for water-stress studies. Plant and Soil, v. 39, n. 01, p. 205-207, 1973.

BERNARDO, S.; SOARES, A. A.; MANTOVANI, E. C. Manual de Irrigação. 8. Ed. Viçosa, MG: UFV, 2006. 625 p.

CALVET, A. S. F.; PINTO, C. M.; LIMA, R. E. M.; MAIA-JOCA, R. P. M.; BEZERRA, M. A. Crescimento e acumulação de solutos em feijão-caupi irrigado com águas de salinidade crescente em diferentes fases de desenvolvimento. Irriga, v. 18, n. 1, p. 148159, 2013. 
COSTA, P. H. A.; SILVA, J. V.; BEZERRA, M. A.; ENEAS FILHO, J.; PRISCO, J. T.; GOMES FILHO, E. Crescimento e níveis de solutos orgânicos e inorgânicos em cultivares de Vigna unguiculata submetidos à salinidade. Revista Brasileira de Botânica, v. 26, n.3, p.289-297, 2003.

DUBOIS, M.; GILLES, K.A.; HAMILTON, J.K.; REBERS, P.A.; SMITH, F. Colorimetric method for determination of sugars and related substances. Analytical Chemistry, Washington, v.28, n.3, p.350-356, 1956.

EMPRESA BRASILEIRA DE PESQUISA AGROPECUÁRIA - EMBRAPA. Sistema brasileiro de classificação de solos. 3.ed. Brasília, 2013. 353p.

HOLANDA, J. S. de; AMORIM, J. R. A. de. Qualidade da água para irrigação. In: GHEYI, H. R., QUEIROZ, J. E.; MEDEIROS, J. F. de. (Ed.). Manejo e controle de salinidade em agricultura irrigada. Campina Grande: SBEA/UFPB, 1997. cap. 5. p. 1-27.

KELLER, J.; KARMELI, D. Trickle irrigation design. S.1: Rain Bird Sprinkler Manufacturing Corporation, 1975. 133 p.

LACERDA, C. F.; SOUSA, G. G.; SILVA, F. L. B.; GUIMARÃES, F. V. A.; SILVA, G. L.; CAVALCANTE, L. F. Soil salinization and maize and cowpea yield in the crop rotation system using saline waters. Engenharia Agrícola, v.31, n.4, p.663-675, 2011.

LARCHER, W. Ecofisiologia Vegetal. Tradução: Carlos Henrique B. A. Prado. São Carlos - SP: Rima, 2006. 529p.

LIMA, C. J. G. S.; OLIVEIRA, F. A.; MEDEIROS, J. F.; OLIVEIRA, M. K. T.; ALMEIDA JÚNIOR, A. B. Resposta do feijão caupi a salinidade da água de Irrigação. Revista Verde, v. 2, n. 2, p. 79-86, 2007.

LIU, J.; ZHU, J. K. An Arabidopsis mutant that requires increased calcium for potassium nutrition and salt tolerance. Proc Natl Acad Sci, USA, 94, p. 14960-14964. 1997.

MUNNS, R.; HUSAIN, S. RIVELLI, A. R.; RICHARD, A. J.; CONDON, A. G.; MEGAN, P. L.; EVANS, S. L.; SCHACHTMAN, D. P.; HARE, R.A. Avenues for increasing salt tolerance of crops, and the role of physiologically based selection traits. Plant and Soil, v.247, p. 93-105, 2002.

NEVES, A. L. R.; LACERDA, C. F.; GUIMARÃES, F. V. A.; HERNANDEZ, F. F. F.; SILVA, F. B.; PRISCO, J. T.; GHEYI, H. R. Trocas gasosas e teores de minerais no feijão de corda irrigado com água salina em diferentes estádios. Revista Brasileira de Engenharia Agrícola e Ambiental, v. 13, suplemento, p. 873- 881, 2009.

PEDROSO, F. K.J.V.; PRUDENTE, D. A.; BUENO, A. C. R.; MACHADO, E. C.; RIBEIRO, R. V. Drought tolerance in citrus trees is enhanced by rootstock dependentchanges in root growth and carbohydrate availability. Environmental and Experimental Botany, v.101, s.n, p. 26 - 35, 2014.

PRAXEDES, S.C.; DAMATTA, F.M.; LACERDA, C.F.; PRISCO, J. T.; GOMES FILHO, E. Salt stress tolerance in cowpea is poorly related to the ability to cope with oxidative stress. Acta Botanica Croatica, v. 73, n. 1, 2014.

PRAZERES, S.S.; LACERDA, C.F.; BARBOSA, E.L.B.; AMORIM, A.V.; ARAUJO, I.C.S.; CAVALCANTE, L.F. Crescimento e trocas gasosas de plantas de feijão-caupi sob irrigação salina e doses de potássio. Revista agro@mbiente On-line, v. 9, n. 2, p. 111-118, 2015.

RHOADES, J. P.; KANDIAH, A.; MASHALI, A. M. The use saline waters for crop production. Trad.: GHEYI, H. R.; SOUSA, J. R.; QUEIROZ, J. E. Campina Grande: UFPB, 2000. 117p. 
SILVA, F. L. B.; LACERDA, C. F.; SOUSA, G. G.; NEVES, A. L. R.; SILVA, G. L.; SOUSA, C. H. C. Interação entre salinidade e biofertilizante bovino na cultura do feijãocaupi. Revista Brasileira de Engenharia Agrícola e Ambiental, v. 15, n. 4, p.383-389, 2011.

SOUSA, G.G.; VIANA, T.A.; LACERDA,C.F.; AZEVEDO,B.M.; SILVA, G.L.; COSTA,F.R.B. Estresse salino em plantas de feijão-caupi em solo com fertilizantes orgânicos. Revista Agro@mbiente On-line, v. 8, n. 3, p. 359367, 2014.

SOUSSI, M.; LLUCH, C.; OCANA, A. Comparative study of nitrogen fixation and carbon metabolism in two chickpea (Cicer arietinum L.) cultivars under salt stress. Journal of Experimental Botanic, v.50, p.1701-1708, 1999.

SOUZA, E. R. de; FREIRE, M. B. G. dos S.; NASCIMENTO, C. W. A. do; MONTENEGRO, A. A. de A.; FREIRE, F. J.; MELO, H. F. de. Fitoextração de sais pela Atriplex nummularia lindl. sob estresse hídrico em solo salino sódico. Revista Brasileira de
Engenharia Agrícola e Ambiental, v.15, n.5, p.477-483, 2011.

SOUZA, M. S. M.; BEZERRA, F. M. L.; TEÓFILO, E. M. Coeficientes de cultura do feijão caupi na região litorânea do Ceará. Irriga, v.10, n.3, p.241-248, 2005.

TAIZ, L.; ZEIGER, E. Fisiologia vegetal. 5.ed. Porto Alegre: Artmed, 2013. 918p.

TRAVASSOS, K. D.; GHEYI, H. R.; SOARES, F. A. L.; BARROS, H. M. M.; DIAS, N. S.; UYEDA, C. A.; SILVA, F. V. Crescimento e desenvolvimento de variedades de girassol irrigado com água salina. Revista Irriga, edição especial, p.324 339, 2012.

WILLADINO, L.; CAMARA, T.R. Origen y naturaleza de los ambientes salinos. In: Reigosa, M.J.; Pedrol, N.; Sánchez, A. (eds). La Ecofisiología Vegetal - Una ciencia de síntesis. Madrid. Thomson. 2004. cap. 10, p. 303-330.

YEMM, E. W.; COCKING, E. C. The determination of amino-acids with ninhydrin. Analyst, v. 80, n. 948, p. 209-213, 1955. 